\title{
Nanocomposite SAC Solders: The Effect of Adding Ni and Ni-Sn Nanoparticles on Morphology and Mechanical Properties of Sn-3.0Ag-0.5Cu Solders
}

\author{
A. YAKYMOVYCH $® i,{ }^{1,2,5}$ P. ŠVEC SR., ${ }^{3}$ L. OROVCIK,${ }^{4}$ O. BAJANA,${ }^{4}$ \\ and H. IPSER ${ }^{1}$ \\ 1.-Department of Inorganic Chemistry - Functional Materials, Faculty of Chemistry, University \\ of Vienna, Althanstr. 14, Währinger Str. 42, 1090 Vienna, Austria. 2.-Department of Metal \\ Physics, Ivan Franko National University, Kyrylo and Mephodiy Str. 8, Lviv 79005, Ukraine. \\ 3.-Department of Metal Physics, Institute of Physics, Slovak Academy of Sciences, Dubravska \\ Cesta 9, 84511 Bratislava, Slovakia. 4.-Institute of Materials and Machine Mechanics, Slovak \\ Academy of Sciences, Dubravska Cesta 9, 84511 Bratislava, Slovakia. 5.-e-mail: \\ andriy.yakymovych@univie.ac.at
}

This study investigates the effect of minor additions of $\mathrm{Ni}, \mathrm{Ni}_{3} \mathrm{Sn}$ or $\mathrm{Ni}_{3} \mathrm{Sn}_{2}$ nanoparticles on the microstructure and mechanical properties of $\mathrm{Cu} /$ solder/ $\mathrm{Cu}$ joints. The nanocomposite $\mathrm{Sn}-3.0 \mathrm{Ag}-0.5 \mathrm{Cu}$ (SAC305) solders with $0.5,1.0$ and $2.0 \mathrm{wt} . \%$ metallic nanoparticles were prepared through a paste mixing method. The employed $\mathrm{Ni}$ and $\mathrm{Ni}-\mathrm{Sn}$ nanoparticles were produced via a chemical reduction method. The microstructure of as-solidified $\mathrm{Cu} / \mathrm{solder} / \mathrm{Cu}$ joints was studied by x-ray diffraction and scanning electron microscopy. The results showed that additions of $\mathrm{Ni}$ and $\mathrm{Ni}-\mathrm{Sn}$ nanoparticles to the SAC305 solder paste lead initially to a decrease in the average thickness of the intermetallic compound layer in the interface between solder and substrate, while further additions up to $2.0 \mathrm{wt} . \%$ did not induce any significant changes. In addition, shear strength and microhardness tests were performed to investigate the relationship between microstructure and mechanical properties of the investigated solder joints. The results indicated an increase in both of these properties which was most significant for the solder joints using SAC305 with 0.5 wt.\% $\mathrm{Ni}$ or $\mathrm{Ni}-\mathrm{Sn}$ nanoparticles.

Key words: $\mathrm{Sn} 3.0 \mathrm{Ag} 0.5 \mathrm{Cu}, \mathrm{Ni}$ and Ni-Sn nanoparticles, microstructure, shear strength, microhardness

\section{INTRODUCTION}

So far, the development of commercial solder joints has focused on using lead-free Sn-based solders reinforced with different kinds of nanoparticles. ${ }^{1-4}$ All these studies showed a profound impact of various ceramic and metal nanoparticles (NPs) on the microstructure and mechanical properties of $\mathrm{Sn}-\mathrm{Ag}-\mathrm{Cu}$ (SAC) solders and the corresponding solder joints. For instance, Refs. 5 and 6 showed a reinforced microstructure with relatively

(Received April 28, 2017; accepted September 27, 2017; published online October 16, 2017) small intermetallic compound (IMC) grains homogeneously distributed in the Sn matrix. The noticeable changes in the morphology and thickness of the interfacial IMC layer between solder and substrate for nanocomposite solder joints were shown in Refs. 7 and 8. Furthermore, the additions of NPs to the SAC solders lead to an enhancement of the shear strength, microhardness, wettability and of other properties. ${ }^{9-11}$

In all these studies, it was shown that the additions of different kinds of NPs to the SAC solders lead, in principle, to similar effects. However, the behavior of the employed ceramic nanoinclusions in the Sn-based matrix is fundamentally 
different from that of metallic NPs: metal NPs are dissolved during the soldering process and act through an alloying effect while ceramic NPs act as nuclei for heterogeneous nucleation. The reduction of the average size of the IMC layer at the interface solder/substrate using nanocomposite SAC solders with ceramic nanoinclusions is explained by the formation of a diffusion barrier layer between the solder and the substrate to retard the rapid interfacial reaction. A similar reduction of the IMC layer, compared to unreinforced SAC solder joints, has been described for nanocomposite SAC solders with metallic NPs, such as $\mathrm{Co}, \mathrm{Ni}$, etc., where part of the added metal is apparently dissolved in the compound $\mathrm{Cu}_{6} \mathrm{Sn}_{5}{ }^{7,12}$

Several methods have been developed for the introduction of NPs into the SAC solders. For instance, a paste and flux mixing method was applied to prepare solders in paste form or as nanocomposite flux-solder mixture, respectively. ${ }^{7,8,13,14}$ A conventional planar flow casting 9,15 as well as a roll bonding method ${ }^{16}$ have been used to fabricate nanocomposite solder ribbons. The mixing methods are the most popular ones due to the relatively simple experimental procedure; however, during the reflow process the NPs tend to move with the flux, and it is very difficult to estimate the amount of nanoinclusions actually remaining in the solder.

Among various types of nanoinclusions in the SAC solders, Ni has attracted great interest due to significant beneficial effects, such as improved microhardness ${ }^{6}{ }^{6}$ wettability ${ }^{7}$ and reliability of the solder joints. ${ }^{14}$ For instance, the SAC solders and solder joints with $\mathrm{Ni}$ as alloying element ${ }^{17,18}$ or as addition in form of micro- or NPs were intensively investigated in Refs. 6, 7, 14, and 19-21.

In this work, we report the changes of microstructure and mechanical properties (shear strength and microhardness) of $\mathrm{Cu} / \mathrm{SAC} 305 / \mathrm{Cu}$ solder joints caused by minor additions of $\mathrm{Ni}$ and intermetallic $\mathrm{Ni}_{3} \mathrm{Sn}$ and $\mathrm{Ni}_{3} \mathrm{Sn}_{2} \mathrm{NPs}$. The nanocomposite solders with $0.5,1.0$ and $2.0 \mathrm{wt} . \%$ nanoinclusions were prepared by the paste mixing method. The $\mathrm{Ni}$ and Ni-Sn nanoinclusions modified the morphology of the SAC305 solder joints and had a noticeable influence on the average thickness of the intermetallic layer at the interface between solder and substrate.

\section{EXPERIMENTAL PROCEDURES}

The Sn-3.0Ag-0.5Cu (SAC305) solder paste provided by Kester (USA) and home-made nanopowders of $\mathrm{Ni}, \mathrm{Ni}_{3} \mathrm{Sn}$ and $\mathrm{N}_{3} \mathrm{Sn}_{2}$ were mixed together in a mortar within a glovebox for at least $30 \mathrm{~min}$ to form nanocomposite solders at a nominal percentage of $0.5,1.0$ and $2.0 \mathrm{wt} . \%$ (related to the mass of the solder in the paste). It was found that $30 \mathrm{~min}$ should be enough to achieve a homogeneous distribution of NPs in the solder paste. ${ }^{6,7}$
The Ni and Ni-Sn NPs were produced via a chemical reduction method employing hydrazine hydrate $\left(\mathrm{N}_{2} \mathrm{H}_{4} \cdot \mathrm{H}_{2} \mathrm{O} ; \quad\right.$ Sigma-Aldrich $)$ and polyvinylpyrrolidone (PVP; Alfa-Aesar) as reducing and surfactant agents, respectively. Nickel chloride $\left(\mathrm{NiCl}_{2}\right.$; Loba-Chemie, Austria) and tin(II)-2-ethylhexanoate $\left(\mathrm{C}_{16} \mathrm{H}_{30} \mathrm{O}_{4} \mathrm{Sn}\right.$; Alfa-Aesar $)$ were dissolved in diethylene glycol (DEG; Alfa-Aesar) as the metal precursors. The average size of the produced $\mathrm{Ni}$ and Ni-Sn NPs was about $100 \mathrm{~nm}$ (Fig. 1). The experimental procedure was described in detail elsewhere. $^{22}$

The solder joints were produced using 3-mm-thick $\mathrm{Cu}$ disks with diameters of $10 \mathrm{~mm}$ and $15 \mathrm{~mm}$ as substrates. Before laying down the nanocomposite solder paste, the $\mathrm{Cu}$ plates were ground and polished with $1-\mu \mathrm{m}$ and $0.3-\mu \mathrm{m} \mathrm{Al}_{2} \mathrm{O}_{3}$ powders, cleaned with ethanol and immerged into a 10 vol.\% sulfuric acid solution (10 vol.\% $\mathrm{H}_{2} \mathrm{SO}_{4}+90$ vol. $\left.\% \mathrm{C}_{2} \mathrm{H}_{5} \mathrm{OH}\right)$ for $2 \mathrm{~min}$ to remove the oxide layer on the surface. The $\mathrm{Cu} /$ solder $/ \mathrm{Cu}$ holders were placed into an electric resistance furnace, and the joints were prepared in air atmosphere by heating at $523 \mathrm{~K}$ for $300 \mathrm{~s}$ (Fig. 2). After the reflow, the solder joints were cleaned to remove any flux residue.

One part of the reflowed samples was crosssectioned and polished with $1-\mu \mathrm{m}$ and $0.3-\mu \mathrm{m}$ $\mathrm{Al}_{2} \mathrm{O}_{3}$ powders for microstructure analysis. The microstructure of the joints was studied by scanning electron microscopy (SEM; JEOL JSM 6610 and JEOL JSM-7600F equipped with an energy dispersive x-ray (EDX) analyzer [Oxford Instruments (OI), $\mathrm{X}$-max $50 \mathrm{~mm}^{2}$ ]. For surface observation, the COMPO and the SEI mode were used. The average thickness of the IMC layer at the interface between the solder and the substrate was calculated using the Digimizer software, freely available in the Internet. $^{23}$ The following equation was used to calculate the average thickness, $x$ :

$$
x=S / L
$$

where $L$ is the length, and $S$ is the integral contour area of the intermetallic layer at the interface.

Another part of the produced samples was used for measurements of mechanical properties. The shear strength studies were performed by the pushoff method (Zwick/Roell Z 100), employing a shearing speed of $1 \times 10^{-3} \mathrm{~m} \mathrm{~min}^{-1}$. The microhardness was measured using a Microhardness Tester (FM100, Future-Tech Corp.). The square-based pyramidal diamond was pressed using a force of $0.05 \mathrm{~N}$ for a loading time of $10 \mathrm{~s}$; at least eight areas across each joint were tested in our measurements to obtain an average value.

\section{RESULTS AND DISCUSSION}

\section{Microstructure Analysis}

The effect of the addition of the metallic NPs on the growth of IMC particles in the bulk solder and 

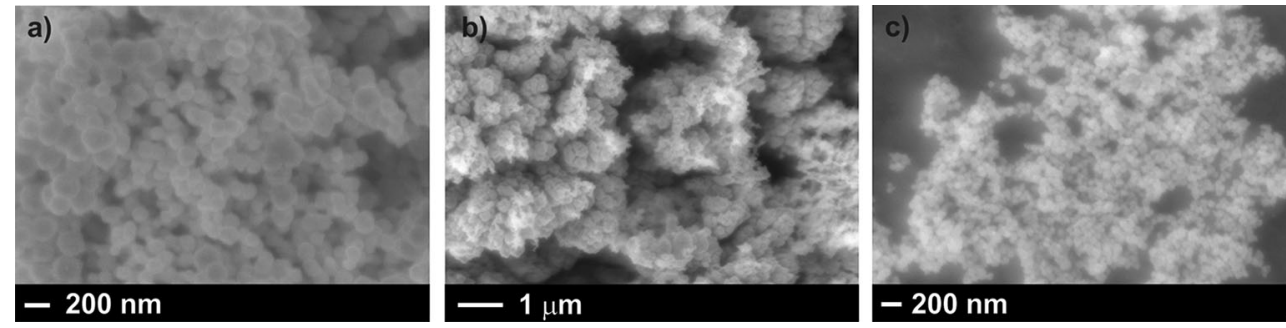

Fig. 1. SEM micrographs of $\mathrm{Ni}(\mathrm{a}), \mathrm{Ni}_{3} \mathrm{Sn}(\mathrm{b})$ and $\mathrm{Ni}_{3} \mathrm{Sn}_{2}$ (c) nanoparticles.

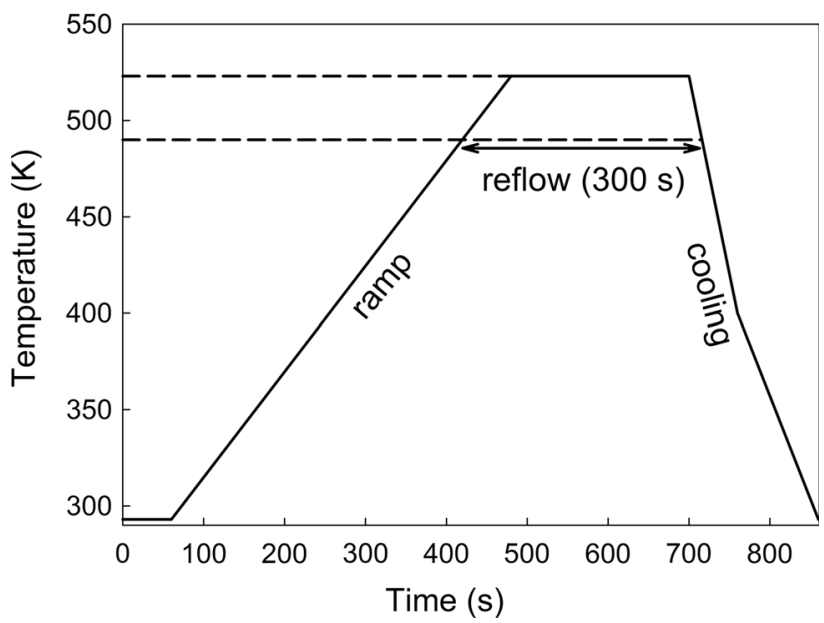

Fig. 2. Reflow temperature profile of solder/Cu joint.

at the interface of solder/Cu was investigated based on SEM of the prepared solder joints. It could be shown that the initial addition of pure Ni lead to a reinforcement of the microstructure of the bulk solder, i.e. the IMC grains were much smaller in the reinforced solder matrix as compared to the unreinforced sample (Figs. 3a and b). The same tendency was determined for solder joints with 1.0 and 2.0 wt.\% Ni (Figs. 3c and d).

Furthermore, the addition of Ni NPs to the SAC305 solder joints lead to changes in the morphology of the interfacial IMC layer from the scallop type layer, typical for SAC solder joints (Fig. 3a), to a more planar-type shape (Figs. 3b-d). Similar changes were indicated for solder joints with nano $\mathrm{Ni}_{3} \mathrm{Sn}_{2}$ and nano $\mathrm{Ni}_{3} \mathrm{Sn}$ additions. The same effect, i.e. a transformation of the IMC layer to a more planar shape with additions of nano $\mathrm{Ni}$, was already observed in Refs. 7 and 14.

In view of this fact, we performed elemental mapping of the IMCs in the bulk solder and at the interface layer of the investigated solder joints. Similar to our previous studies dealing with nanocomposite SAC solder joints with metal and ceramic nanoadditions, ${ }^{8,9}$ a $\mathrm{Cu}_{6} \mathrm{Sn}_{5} / \mathrm{Cu}_{3} \mathrm{Sn}$ double layer was observed at the solder/Cu interface. It was found that $\mathrm{Ni}$ atoms were incorporated into the $\mathrm{Cu}_{6} \mathrm{Sn}_{5}$ crystals, both in the bulk solder and in the interfacial layer, while no regions with either pure
$\mathrm{Ni}$ or Ni-Sn IMCs could be seen in the joints. As an example, Fig. 4 presents the cross-sectional microstructure of solder $/ \mathrm{Cu}$ solder joints without (a) and with 1.0 wt.\% $\mathrm{Ni}$ (b), $\mathrm{Ni}_{3} \mathrm{Sn}$ (c) and $\mathrm{Ni}_{3} \mathrm{Sn}_{2}$ (d) nanoinclusions, respectively. This phenomenon can be explained by the assumption that $\mathrm{Ni}$ and $\mathrm{Ni}$ Sn particles were completely dissolved during the ramp and the reflow and $(\mathrm{Ni}, \mathrm{Cu})_{6} \mathrm{Sn}_{5}$ crystals were formed during cooling. At the same time, no traces of $\mathrm{Ni}$ were found in the $\mathrm{Cu}_{3} \mathrm{Sn}$ and $\mathrm{Ag}_{3} \mathrm{Sn}$ phases. $\mathrm{A}$ very similar observation was made in previous studies dealing with nanocomposite SAC solders with nano Ni. ${ }^{7}$ It should also be noted that the relatively small light spheres in the presented micrographs (Fig. 3 and 4) correspond to $\mathrm{Ag}_{3} \mathrm{Sn}$ grains homogeneously distributed in the bulk solder and dispersed on the surface of the interfacial IMC layer.

An EDX analysis of the $(\mathrm{Cu}, \mathrm{Ni})_{6} \mathrm{Sn}_{5} \mathrm{IMC}$, both in the bulk solder and in the interface layers, was performed for all investigated solder joints (see Table I), and this showed clearly that $\mathrm{Ni}$ atoms replace $\mathrm{Cu}$ in $\mathrm{Cu}_{6} \mathrm{Sn}_{5}$ according to its typical concentrations in the solder. The outer IMC layers at the interface solder/Cu and the IMCs in the solder matrix contained about 2 at. $\% \mathrm{Ni}$ while the concentration of $\mathrm{Ni}$ in the IMC in the bulk solder near the interfacial layer reached about 17 at.\%. These data are in agreement with results from Ref. 24 where a possible dissolution of 21.4 at.\% Ni in $\mathrm{Cu}_{6} \mathrm{Sn}_{5}$ was shown. The higher amount of $\mathrm{Ni}$ in $(\mathrm{Cu}, \mathrm{Ni})_{6} \mathrm{Sn}_{5}$ grains located in the solder matrix close to the interface compared to its concentration in the interfacial IMC layer was explained in Ref. 6 .

It should also be noted that the amount of dissolved $\mathrm{Ni}$ in $(\mathrm{Cu}, \mathrm{Ni})_{6} \mathrm{Sn}_{5}$ grains, both in the solder matrix and at the interface, was smaller when Ni-Sn intermetallic NPs were added to the SAC solder than for pure Ni NPs (Table I). Furthermore, according to the elemental mapping of solder/Cu joints with $\mathrm{Ni}_{3} \mathrm{Sn}$ and $\mathrm{Ni}_{3} \mathrm{Sn}_{2}$ nanoinclusions, there are some areas in the interfacial IMC layer, which did not contain $\mathrm{Ni}$ at all. This observation is rather difficult to explain; however, it is clear that the total amount of $\mathrm{Ni}$ is less in the Ni-Sn NPs than in the pure Ni NPs. In addition, it is to be expected that the dissolution of the Ni-Sn NPs is slower due to the tin oxide/hydroxide shell that is to be expected on their surface. 

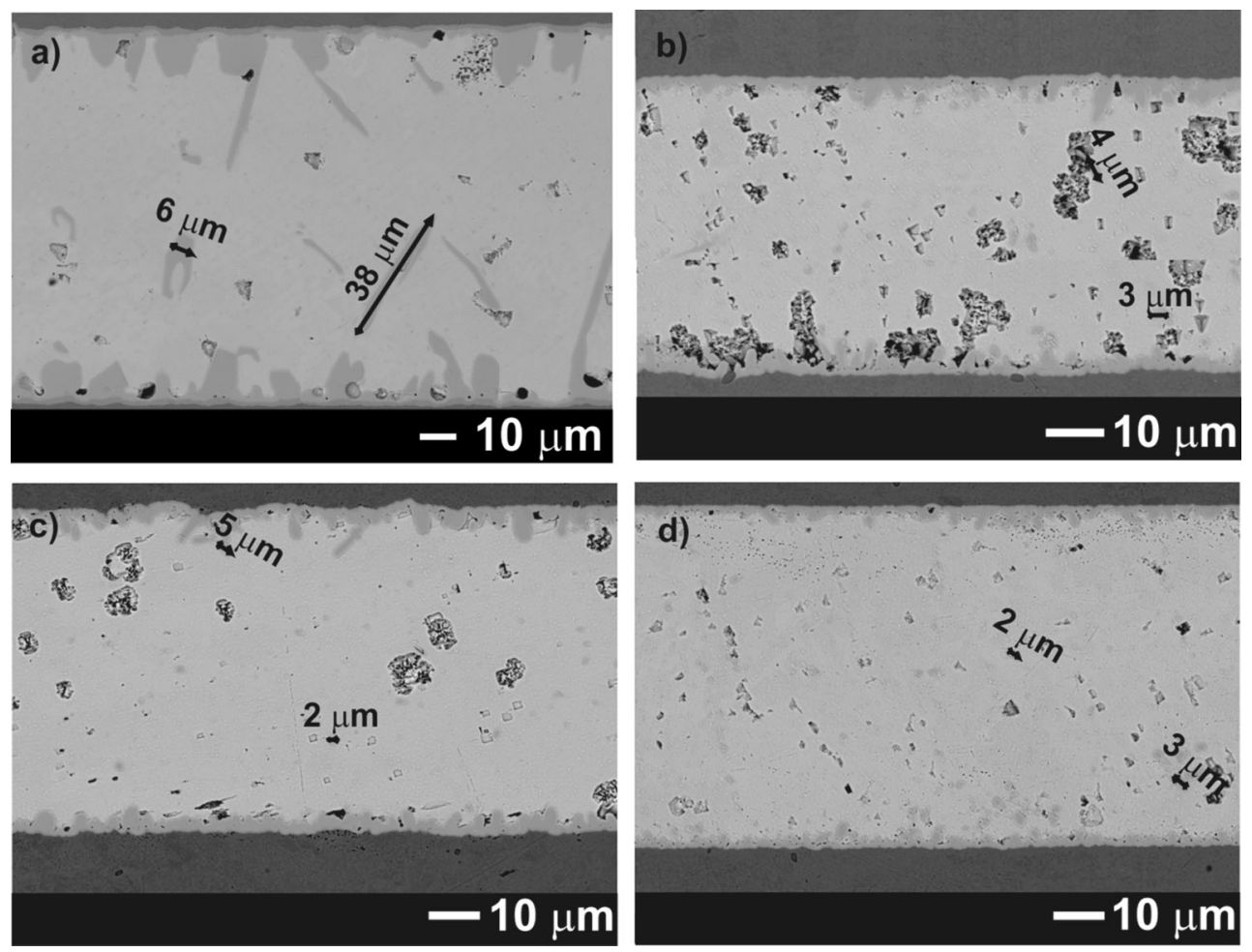

Fig. 3. SEM micrographs of as-solidified SAC305 (a) and SAC305-Ni solder joints with 0.5 (b), 1.0 (c) and 2.0 wt.\% Ni (d).
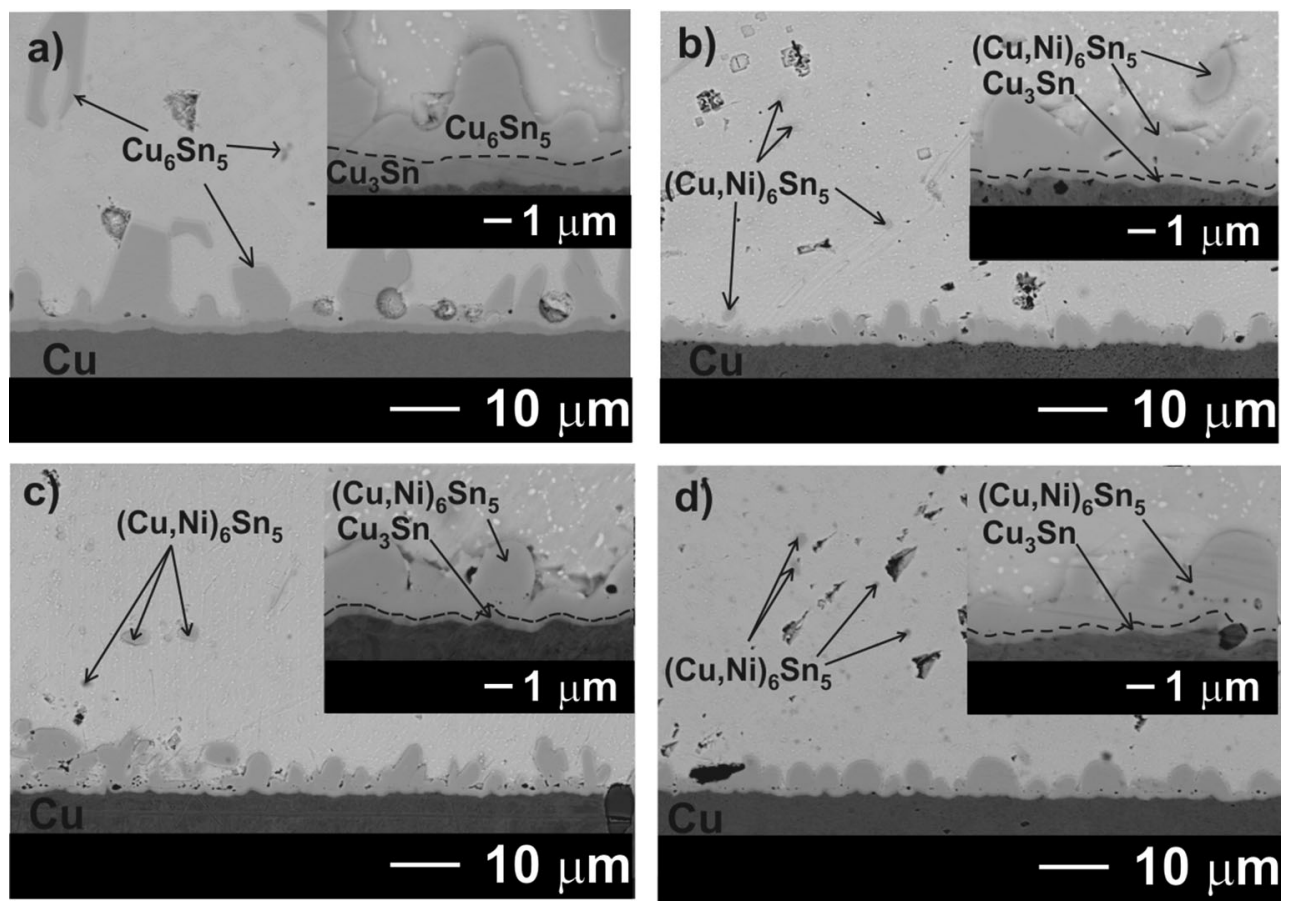

Fig. 4. SEM micrographs of as-solidified SAC305 (a) and SAC305 solder joints with 1.0 wt.\% Ni (b), $\mathrm{Ni}_{3} \mathrm{Sn}_{\text {(c) }}$ and $\mathrm{Ni}_{3} \mathrm{Sn}_{2}$ (d).

Figure 5 shows the average thickness of the interfacial $(\mathrm{Cu}, \mathrm{Ni})_{6} \mathrm{Sn}_{5}+\mathrm{Cu}_{3} \mathrm{Sn}$ layer between solder and $\mathrm{Cu}$ substrate. Initial additions of nanoinclusions lead to a decrease of the average thickness while the most significant drop was obtained for the SAC305 solder joints with additions of $0.5 \mathrm{wt} . \%$ nano Ni. Further additions of nano $\mathrm{Ni}_{3} \mathrm{Sn}$ up to $2.0 \mathrm{wt} . \%$ lead to an insignificant increase of the 
Table I. EDX analysis of $(\mathrm{Cu}, \mathrm{Ni})_{6} \mathrm{Sn}_{5}$ grains in the bulk solder and in the interface layer

\begin{tabular}{|c|c|c|c|c|}
\hline Solder alloy & Location of $(\mathrm{Cu}, \mathbf{N i})_{6} \mathbf{S n}_{5}$ & Cu (in at.\%) & Sn (in at.\%) & $\mathrm{Ni}$ (in at.\%) \\
\hline $\mathrm{SAC} 305+\mathrm{Ni}$ & Outer interfacial layer & $54.9-57.2$ & $41.3-43.9$ & $1.1-1.7$ \\
\hline \multirow{3}{*}{$(0.5,1.0$ and 2.0 wt. $\%)$} & Grains close to interfacial layer & $37.7-40.2$ & $44.9-54.0$ & $5.0-17.4$ \\
\hline & Solder matrix & $55.1-56.4$ & $42.6-42.1$ & $1.1-2.4$ \\
\hline & & $55.9-57.4$ & $42.6-44.1$ & ${ }^{1.1}$ \\
\hline $\mathrm{SAC} 305+\mathrm{Ni}_{3} \mathrm{Sn}$ & Outer interfacial layer & $53.4-58.7$ & $39.8-45.4$ & $0.8-2.2$ \\
\hline \multirow[t]{3}{*}{$(0.5,1.0$ and 2.0 wt. $\%)$} & Grains close to interfacial layer & $41.2-56.8$ & $41.9-52.0$ & $1.3-6.8$ \\
\hline & Solder matrix & $55.8-56.9$ & $41.9-42.3$ & $1.1-1.9$ \\
\hline & & $57.6-57.7$ & $42.3-42.4$ & - \\
\hline $\mathrm{SAC} 305+\mathrm{Ni}_{3} \mathrm{Sn}_{2}$ & Outer interfacial layer & $52.1-58.9$ & $40.0-46.8$ & $0.1-1.4$ \\
\hline \multirow{3}{*}{$(0.5,1.0$ and 2.0 wt. $\%)$} & Grains close to interfacial layer & $44.4-59.0$ & $40.5-50.6$ & $0.5-4.0$ \\
\hline & Solder matrix & $55.3-56.4$ & $42-43.1$ & $0.2-1.6$ \\
\hline & & $54.2-56.9$ & $43.1-45.8$ & - \\
\hline
\end{tabular}

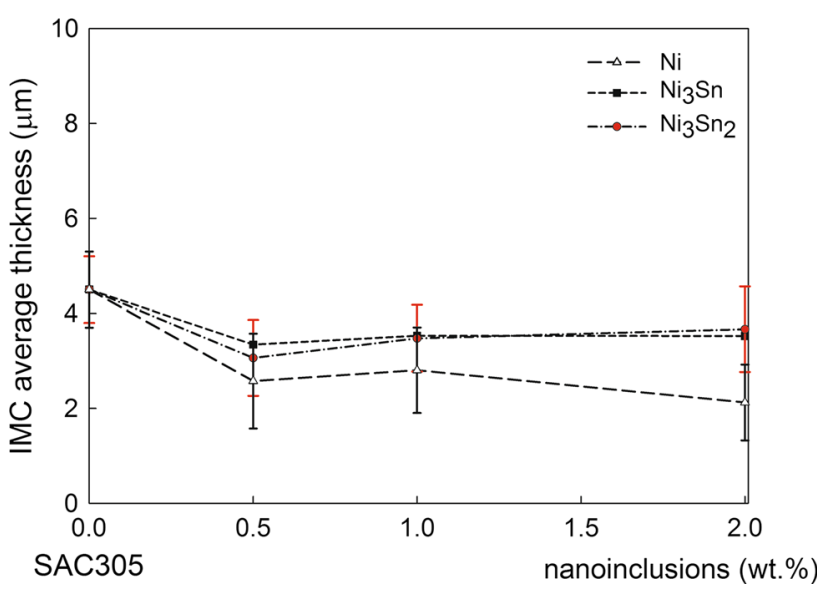

Fig. 5. The average thickness of the $\left(\mathrm{Cu}, \mathrm{Ni}_{6} \mathrm{Sn}_{5}+\mathrm{Cu}_{3} \mathrm{Sn}\right.$ interface layer.

average thickness while the concentration dependence of the average thickness of the $(\mathrm{Cu}, \mathrm{Ni})_{6} \mathrm{Sn}_{5}+\mathrm{Cu}_{3} \mathrm{Sn}$ IMC layer at the solder $/ \mathrm{Cu}$ interface shows a plateau for SAC305 solder joints with $0.5-2.0$ wt.\% nano $\mathrm{Ni}_{3} \mathrm{Sn}_{2}$. In contrast, the addition of 1.0 wt.\% Ni to the SAC305 solder did not affect the average thickness of the interface IMCs layer while a further decrease was indicated for SAC305 solder joints with 2.0 wt.\% Ni NPs. It should also be noted that a gradual transformation of the morphology of the interfacial layer from the typical scallop to a more planar type was indicated for the SAC305 solder joints with further additions of both $\mathrm{Ni}$ and Ni-Sn NPs. At the same time, the thickness of the thin $\mathrm{Cu}_{3} \mathrm{Sn}$ layer in the interface zone was about $0.3 \mathrm{~mm}$ for all investigated solder joints. The present results are in a good agreement with literature data on the average thickness of the interfacial IMC layer for SAC305 + $0.5 \mathrm{wt} . \%$ nano $\mathrm{Ni} / \mathrm{Cu}(2.42 \mu \mathrm{m}$; Ref. 6$)$, but in some disagreement with literature data on SAC305 + $2.0 \mathrm{wt} . \%$ nano Ni/ $\mathrm{Cu}(3.9 \mu \mathrm{m}$; Ref. 14). However, it should be pointed out that the solders for the joints investigated in Ref. 14 were prepared by the flux mixing method where Ni NPs were concentrated in the flux between SAC solder ball and $\mathrm{Cu}$ substrate.

Based on the observations presented above, adding $\mathrm{Ni}$ in nanosized form to the SAC solders has several advantages compared to the addition of $\mathrm{Ni}$ in bulk form:

- Nanoadditions lead to a transition of the morphology of the interfacial IMC layer from a scallop to a more planar type, which should improve the joint strength, while needle-like microstructures were observed in SAC solder joints with bulk $\mathrm{Ni}$ additions which might deteriorate the mechanical properties; ${ }^{17,25}$

- In contrast to the bulk, nanoinclusions did not lead to the formation of large amounts of $(\mathrm{Cu}, \mathrm{Ni})_{6} \mathrm{Sn}_{5}$ grains near the solder/Cu interface as well as to a growth of the average thickness of the interfacial IMC layer. ${ }^{18}$

\section{Mechanical Properties}

The shear strength of the SAC solder joints with $\mathrm{Ni}$ and Ni-Sn nanoinclusions is presented in Fig. 6. A significant increase of the shear strength by initial additions of NPs to the SAC305 solder was found for all employed NPs while further additions did not show any considerable improvement of this mechanical property. It should be noted that the growth of brittle IMC layers at the interface solder/substrate affects the reliability of the solder joint considerably, in particular the shear strength. Therefore, the observed changes in the morphology and thickness of the interfacial layer should be directly connected with changes of the shear strength. In the present case, it was established that a noticeable decrease in the average thickness lead to an increase in the shear strength from $30 \mathrm{MPa}$ up to $47 \mathrm{MPa}$.

The postulated reinforcement of the microstructure in the bulk solder should lead to an enhancement of the microhardness due to the pinning effect. The finely distributed small-sized particles (in the 


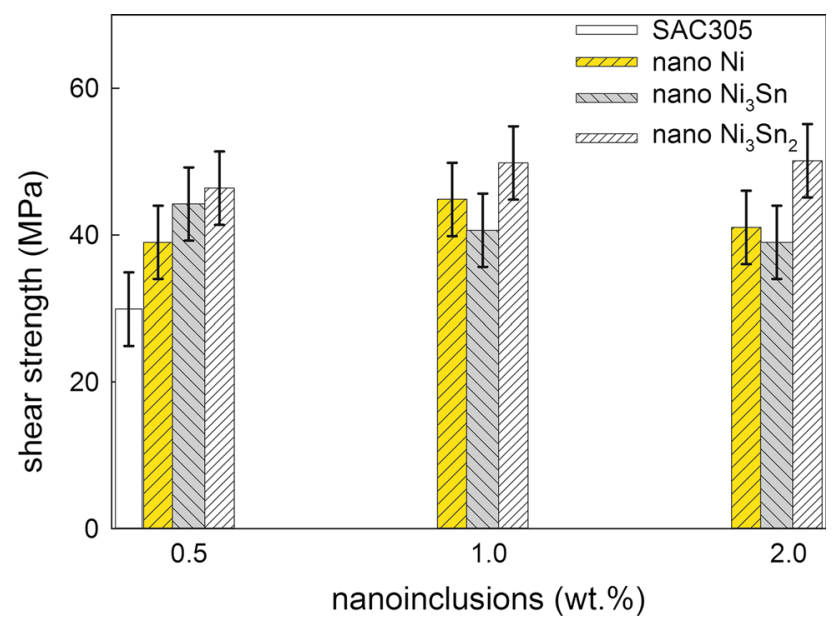

Fig. 6. The shear strength of the nanocomposite SAC305 solder joints as a function of the amount of Ni and Ni-Sn NPs.

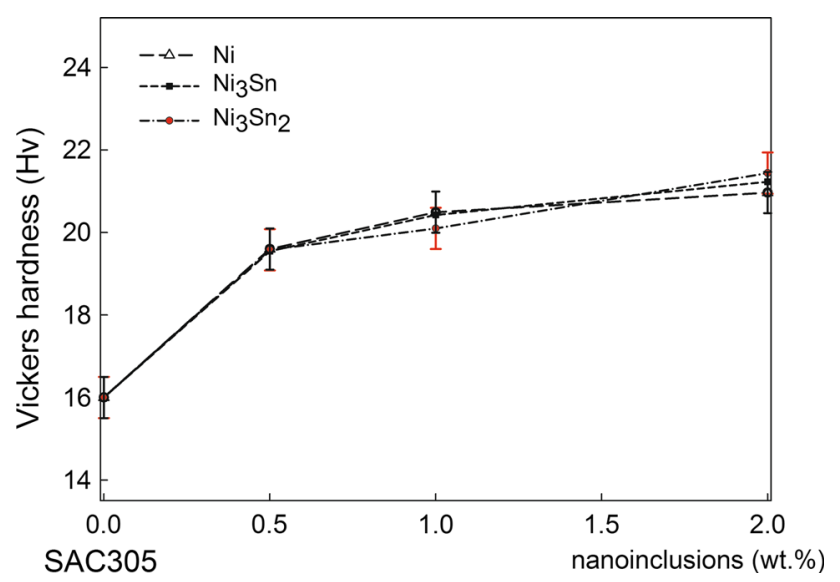

Fig. 7. The Vickers hardness of the nanocomposite SAC305 solder joints as a function of the amount of $\mathrm{Ni}$ and $\mathrm{Ni}-\mathrm{Sn}$ nanoinclusions.

present case, $\mathrm{Ag}_{3} \mathrm{Sn}$ and $\left.\mathrm{Cu}_{6} \mathrm{Sn}_{5} /(\mathrm{Cu}, \mathrm{Ni})_{6} \mathrm{Sn}_{5}\right)$ improve the solder deformation resistance. According to the results presented in Fig. 7, the major effect of the addition of NPs was obtained for $0.5 \mathrm{wt} . \%$ of nanoinclusions. Further additions up to $2.0 \mathrm{wt}$.\% improved the microhardness of the bulk SAC305 solder, however, less significantly compared to the initial addition. Such a significant increase in the microhardness for SAC305 solder (about $11 \%$ ) with the addition of $0.5 \mathrm{wt} . \%$ nano $\mathrm{Ni}$ was also indicated by Gain and Chan. ${ }^{6}$

Finally, it should also be noted that we cannot estimate the exact amount of nano $\mathrm{Ni}$ which remained in the solder joints after the reflow process. The chemical analysis of the reinforced SAC solders with Ni NPs performed by Tay et al. ${ }^{7}$ determined, for example, that for the addition of 2.0 wt.\% NPs, only 0.29 wt.\% Ni were left in the solder after the reflow.

\section{CONCLUSIONS}

Based on the present results, a complete dissolution of the employed nanoinclusions into the SAC305 solder during the reflow process is suggested. The major effects on the microstructure and mechanical properties of the SAC305 solder joints were caused by the initial additions of $\mathrm{Ni}, \mathrm{Ni}_{3} \mathrm{Sn}$ and $\mathrm{Ni}_{3} \mathrm{Sn}_{2}$ NPs (0.5 wt.\%), while a further increase of the amount of nanoinclusions up to $2.0 \mathrm{wt} . \%$ did not lead to any significant further improvements. The average thickness of the interfacial IMC layer decreases significantly by the addition of nano $\mathrm{Ni}$ compared to the Ni-Sn nanoadditions. In contrast, the effect of the $\mathrm{Ni}, \mathrm{Ni}_{3} \mathrm{Sn}$ and $\mathrm{Ni}_{3} \mathrm{Sn}_{2}$ nanoadditions on the shear strength and the microhardness of the SAC305 solder joint is more or less the same.

\section{ACKNOWLEDGEMENTS}

Open access funding provided by Austrian Science Fund (FWF). Financial support for this study came from the Austrian Science Fund (FWF) under Project Nos. P 26304 and P 27049, and the Slovak Scientific Grant Agency under Project Nos. VEGA 2/ 0172/16 and VEGA 2/0189/14.

\section{OPEN ACCESS}

This article is distributed under the terms of the Creative Commons Attribution 4.0 International License (http://creativecommons.org/licenses/by/4.0/), which permits unrestricted use, distribution, and reproduction in any medium, provided you give appropriate credit to the original author(s) and the source, provide a link to the Creative Commons license, and indicate if changes were made.

\section{REFERENCES}

1. A.T. Tan, A.W. Tan, and F. Yusof, Sci. Technol. Adv. Mat. 16, 033505 (2015).

2. H.R. Kotadia, P.D. Howes, and S.H. Mannan, Microelectron. Reliab. 54, 1253 (2014).

3. L. Zhang and K.N. Tu, Mat. Sci. Eng. R 82, 1 (2014),

4. K. Subramanian, Lead-Free Solders; Materials Reliability for Electronics (Chichester: Wiley, 2012), p. 520.

5. L.C. Tsao, R.W. Wu, T.H. Cheng, K.H. Fan, and R.S. Chen, Mater. Des. 50, 774 (2013).

6. A.K. Gain and Y.C. Chan, Intermetallics 29, 48 (2012).

7. S.L. Tay, A.S.M.A. Haseeb, M.R. Johan, P.R. Munroe, and M.Z. Quadir, Intermetallics 33, 8 (2013).

8. A. Yakymovych, Y. Plevachuk, P. Svec, P. Svec, D. Janikovic, P. Sebo, N. Beronska, A. Roshanghias, and H. Ipser, J. Electron. Mater. 45, 6143 (2016).

9. A. Yakymovych, Y. Plevachuk, P. Svec, D. Janikovic, P. Sebo, N. Beronska, M. Nosko, L. Orovcik, A. Roshanghias, and H. Ipser, J. Mater. Sci. Mater. Electron. 28, 10965 (2017).

10. G. Chen, F.S. Wu, C.Q. Liu, V.V. Silberschmidt, and Y.C. Chan, J. Alloys Compd. 656, 500 (2016).

11. S. Chellvarajoo and M.Z. Abdullah, Mater. Des. 90, 499 (2016).

12. F. Gao, J.M. Qu, and T. Takemoto, J. Electron. Mater. 39, 426 (2010).

13. S.K. Ghosh, A.S.M.A. Haseeb, A. Afifi, Electronics Packaging Technology Conference (EPTC 2013) 21 (2013). doi: 10.1109/EPTC.2013.6745676. 
14. M.N. Bashir, A.S.M.A. Haseeb, A.M.S. Rahman, M.A. Fazal, and C.R. Kao, J. Mater. Sci. 50, 6748 (2015).

15. K. Mehrabi, F. Khodabakhshi, E. Zareh, A. Shahbazkhan, and A. Simchi, J. Alloys Compd. 688, 143 (2016).

16. A. Roshanghias, A.H. Kokabi, Y. Miyashita, Y. Mutoh, M. Rezayat, and H.R. Madaah-Hosseini, J. Mater. Sci. Mater. Electron. 23, 1698 (2012).

17. Y.W. Wang, C.C. Chang, and C.R. Kao, J. Alloys Compd. 478, L1 (2009).

18. Y.W. Wang, C.R. Kao, Electronic Materials and Packaging, 2008 (EMAP 2008) 76 (2008). doi: 10.1109/EMAP.2008.4784233.
19. A. Yakymovych, Y. Plevachuk, V. Sklyarchuk, B. Sokoliuk, T. Galya, and H. Ipser, J. Phase Equilib. Diffus. 38, 217 (2017).

20. P. Yao, P. Liu, and J. Liu, J. Alloys Compd. 462, 73 (2008).

21. P. Liu, P. Yao, and J. Liu, J. Alloys Compd. 486, 474 (2009).

22. A. Yakymovych and H. Ipser, Nanoscale Res. Lett. 12, 142 (2017).

23. Med Calc Software BVBA, Free Image Analysis Software (2016). http://www.digimizer.com.

24. C.H. Wang, W.H. Lai, and S.W. Chen, J. Electron. Mater. 43, 195 (2014).

25. J.Y. Tsai, Y.C. Hu, C.M. Tsai, and C.R. Kao, J. Electron. Mater. 32, 1203 (2003). 